Volume (3) No. (2) 2020

اليقظة العقلية والمرونة النفسية والذكاء الانفعالي كمنبئات بالتعلم الانفعالي الاجتماعي لدى عينة من الطلاب المعلمين بكلية التربية

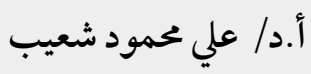


اليقظة العقلية والمرونة النفسية والذكاء الانفعالي كمنبئات بالتعلم الانفعالي الاجتحاعي لدى

عينة من الطلاب المعلمين بكلية التربية

$$
\text { أ.د إ علي محمود شعيب }
$$

أستاذ الصحة النفسية كلية التربية جامعة المنوفية، مصر

Alishoeib2004@icloud.com

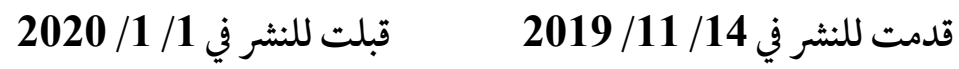

الملخص: هدفت الدراسة الحالية إلى التعرف على قدرة كل من اليقظة العقلية والمرونة النفسية و الذكاء الانفعالي في التنبؤ بالتعلم الانفعالي الاجتحاعي لدىن عينة من الطلاب المعلمين بكلية التربية جامعة المنوفية. وتكونت عينة الدراسة من 286 فردا من الطلاب المعلمين بواقع (254 من الاناث، 28 من الذكور)؛ واستخدمت الدراسة الأدوات التالية: مقياس التعلم الانفعالي - الاجتماعي إعداد ( 2012, Zhou and Ee Jessie) وتعريب الدراسة الحالية؛ مقياس الأوجه الخمسة لليقظة العقلية Five Facet Mindfulness Questionnaire (FFMQ) اعداد THE CONNOR-) وتعريب الدراسة الحالية مقياس المرونة النفسية (Baer,2011) DAVIDSON RESILIENCE SCALE (CD-RISC الذكاء الانفعالي إعداد (شعيب،2013). وأسفرت نتائج الدراسة عن وجود علاقة ارتباطية دالة احصائيا عند مستون 0.01 بين كل من التعلم الانفعالي- الاجتماعي، اليقظة العقلية، المرونة النفسية، والذكاء الانفعالي لدى الطلاب المعلمون من كلية التربية جامعة المنوفية؛ كما أسفرت عن ان المتغيرات: اليقظة العقلية، والذكاء الانفعالي، والمرونة النفسية تساهم في التنبؤ

$$
\text { بالتعلم الانفعالي - الاجتماعي. }
$$

الكلمات الدلالية: التعلم الانفعالي الاجتماعي، اليقظة العقلية، المرونة النفسية، الذكاء الانفعالي. 


\section{Mindfulness, psychological resilience and emotional intelligence as predictors of social emotional learning among a sample of student teachers}

Prof. Dr. Ali Mahmud Shoeib

Professor of Mental Psychology, College of Education, Menoufia University,

Egypt

Alishoeib2004@icloud.com

Received in $14^{\text {th }}$ November $2019 \quad$ Accepted in 1st January 2020

Abstract: The present study aimed at identifying the ability of Mindfulness, psychological resilience and emotional intelligence in predicting social emotional learning among a sample of student teachers at the Faculty of Education, Menoufia University. The sample of the study consisted of 286 student teachers (254 females, 28 males). Instrumentally, the present study used: Emotional-Social Learning Scale by Zhou and Jessie Ee, 2012 (modified to Arabic by the present study), Facility Mindfulness Questionnaire (FFMQ) by Baer, 2011(modified to Arabic by the present study), THE CONNORDAVIDSON RESILIENCE SCALE (CD-RISC 2003) modified to Arabic by the present study), Emotional Intelligence Scale Prepared by (Shoeib, 2012). The study results showed a statistically significant correlation at 0.01 level between emotional-social learning, Mindfulness, psychological resilience, and emotional intelligence among student teachers of the Faculty of Education, Menoufia University. It also results that variables as emotional intelligence, Mindfulness and psychological resilience contribute to the prediction of emotional-social learning.

Keywords: Emotional-social learning, Mindfulness, psychological resilienceemotional intelligence. 
مقدمة

شهد القرن التاسع عشر نشاطا ملحوظا في استباط مفاهيم جديدة للذكاء، فكان الذكاء

الانفعالي Emotional Intelligence (EI) والذكاء الروحي Spiritual Intelligence (SI)، والذكاء الشخصي Personal Intelligence (PI)؛ وكان لظهور علم النفس الإيجابي علن يد Ted Martin Seligman Social - Emotional learning التفكير حولها، فكان ظهور التعلم الانفعالي - الاجتماعي (SEL) الأساسية لجودة الحياة من خلال تدريس كافة المهارات التي تمكننا من التحكم في أنفسنا، وعلاقاتنا، ونمط أعحالنا، بطريقة فاعلة ومكتملة قيميا وأخلاقيا. وتتضمن هذه المهارات التعرف managing انفعالاتنا، كيفية تطوير سبل اهتمامنا بالأخر، كيفية إقامة علاقات إيجابية، واتخاذ القرار المناسب، ضبط مو اقف التحدي والمنافسة بصورة بناءة قيميا واخلاقيا.

وعرف (Mayer and Salovey, 1997,10) الذكاء الانفعالي الاجتهاعي Emotional social intelligence الوصول و / أو توليد المشاعر التي تسهل التفكير؛ القدرة علن فهم العاطفة والمعرفة العاطفية؛ القدرة على تنظيم العو اطف للتعزيز العاطفي والنمو الفكري. ويعتبر الذكاء الانفعالي المصطلح الأكثر استخدامًا في الولايات المتحدة. وينسب إليها ايضا (1990) انها قد ركزا علن الجوانب المعرفية والسلوكية، كما تناو لا مفهوم الذكاء الاجتماعي Social Intelligence (SI) من خلال الاليات الحاكمة للتفاعل بين الفرد والأخرين، والوضع الاجتماعي، والعلاقات السياسية، و النشاطات الشخصية والقيادة. وتزامن أيضا عملهها مع أعمال (1995) Gardner,et al، الذي 
جادل بأن مفهوم الذكاء عموما أوسع بكثير عن المفترض من خلال تفسيره للذكاءات السبعة

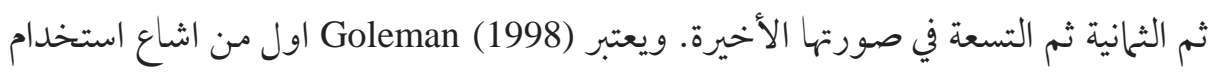

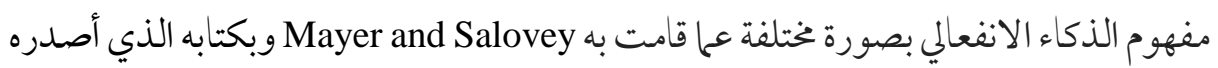
في 1996 بعنو ان Emotional Intelligence الذي يعتبر أحد الركائز الأساسية في فهم الذكاء الانفعالي. ويعتبر مصطلح الذكاء الانفعلي او الاجتماعي من الاثار التاريخية ولعل هذا يبدو واضحا من كتابات (Sternberg, 2001) الذي انتقد وتحفظ في نظريته ثلاثية الابعاد (العاملي، والخبراتي، والبيئي) علن مصطلح الذكاء مقرونا بالانفعال او العواطف حيث ان الذكاء كمصطلح يتضمن ويركز في جوهره علن القياس أكثر من كونه أسلوبا للتدريس او التعلم (احمد،2016). كما ان الذكاء في حد ذاته يمثل قدرة محددة السعة غير قابلة لتنميتها من خلال التدريس او التعلم. وقد لا تظهر قيمة حقيقية لمفهوم الذكاء الانفعالي والاجتماعي في تفسير بعض السلوكيات غير المرغوب فيها (التدخين مثلا) التي نقوم بها رغم امتلاكنا أحيانا للقدرة علن إدراك الانفعالات وفهمها وادارتها. وإذا كان الذكاء الانفعالي او الاجتماعي ذائعا في صيته لئه بالو لايات المتحدة الامريكية كمفهوم للذكاء الا انه يتناظر كلية بمفاهيم تختلف عنه في المعنى في ثقافة البريطانيين مثل: التنور literacy، والمنافسة competence. وفي العام 1997، ظهر مفهوم المنافسة الاجتماعية والانفعالية emotional and Social competence عنها في حياتنا اليومية بها يجعلنا قادرين علن تحقيق النجاح في هذه النشاطات الحياتية مثل التعلم، انشاء العلاقات، حل المشكلات، والتكيف مع المواقف الضاغطة لمطالب النمو والتطور (Topping,,1998) بأنها عملية (Elias,et al.,1997,2) قدرتنا علن دمج التفكير والشعور والسلوك لتحقيق مهه|تنا الاجتماعية وتقييم نتائج ما درسناه

\section{http://dx.doi.org/10.29009/ijres.3.2.2}


بصورة عميقة، بالإضافة المث تلبية الاحتياجات الاجتماعية والانفعالية الشخصية المرتبطة، ونقل

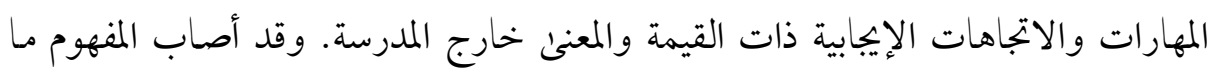

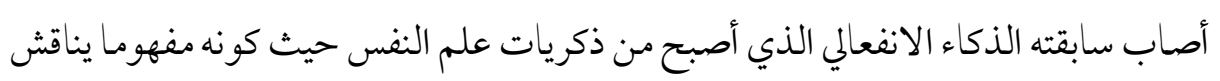
الصراع بين المؤسسات الربحية أكثر من كونه مفهوما تربويا.

وفي العام 2000، تناول Stewart-Brown مفهوم الوجود الانفعلي الاجتماعي

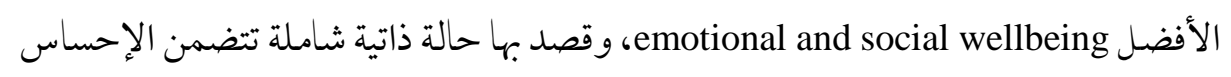
بالطاقة، والثقة بالنفس، والاستمتاع، والسعادة والهدوء، والعطاء، جميعها في حالة مترابطة

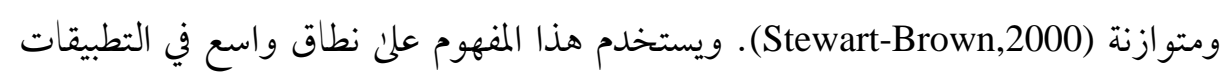

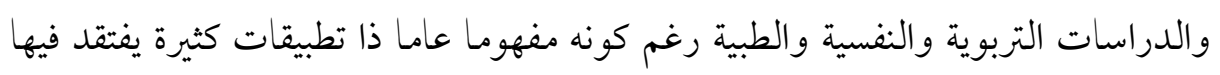
للخصوصية.

وفي العام 2001 وضع Sharp مفهوما جديدا هو التنور الانفعالي Emotional Literacy

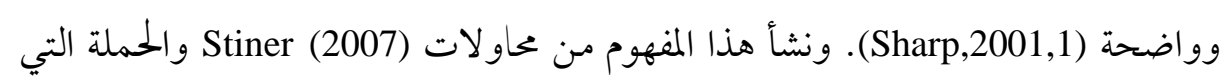

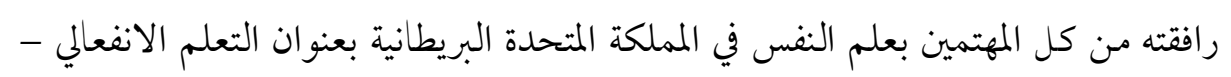

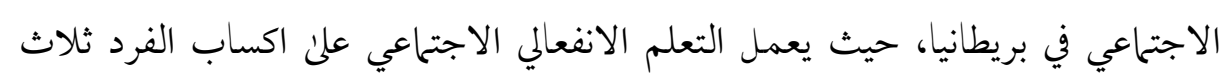

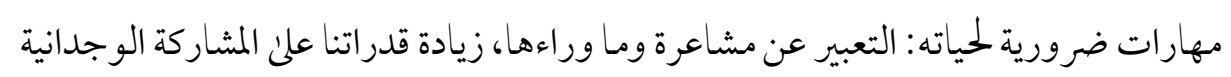

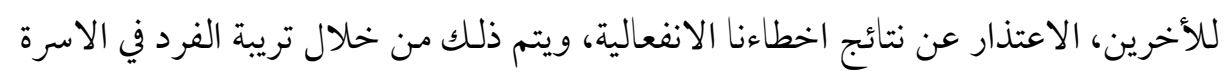
والمدرسة والمجتمع من خلال أنشطة الذكاء النابع من القلب (p.11) intelligence with heart ويصادف المفهوم كثيرا من النقد خاصة في كلمة التنور literacy التي قد تركز كثيرا علن. 
الفرد وامكاناته دون الاهتحام بالمحيط الثقافي الذي يعيش فيه. بالإضافة المي ان الكلمة نفسها قد تستدعي استخدامات غير المطلوبة منها خاصة لدى غير المتخصصين في المجال التربوي. وترى (Garcia,2015,2) أن التعلم الانفعالي - الاجتحاعي social - emotional literacy (SEL) قدرته علن فهم العو اطف و التعبير عنها بشكل مناسب. كما اشارت ان الافر اد الذين لا يتمتعون بالتعلم الانفعالي - الاجتماعي قد لا يصبحون مواطنين اكفاء ويستلزم إعادة تأهيلهم مرة أخرىن. كما ان المدارس التي تقصد تدريس طلابها التعلم الانفعالي - الاجتماعي كجزء خفي في المقررات الدراسية، فانهم يرتقون بمستوكئ أداء طلابهم تحصيليا وعدم هجرتهم للتعليم مستقبلا.

ويشير (Silas,2018) أن مفهوم التعلم الانفعالي الاجتماعي قد ظهر لتنامي الاهتمام بالجانب الاجتحاعي والانفعلي في العقد الأخير، وانه حل بذلك مكان النمو المعرفي والبدني كمؤشر ات للحكم علن الشخصية. ويستطرد قائلا، ان هذا المتغير طبق في دراسات نفسية علن حالات من ذوي الاضطرابات السلو كية بالإضافة المى ذوي صعوبات التعلم بجانب تطبيقه علن الحالات العادية، حيث أوضحت النتائج انه يساعد علن وصول الفرد للحالة الإحساس بالراحة النفسية وتحقيق الرضا عن الذات. ويقصد بالمفهوم تلك القدرة علن الفهم والتعبير عن المشاعر. ويساهم المفهوم في تحسين تقدير الفرد لذاته، وأيضا في تحقيق النمو الاجتماعي للفرد. وقد يتأثر المفهوم بقدرة الفرد على التعبير عن مشاعرة امـا بسبب الإعاقة او بسبب عدم القدرة play علن التفكير في مشاعرنا خوفا من الفشل في القبول الاجتماعي. ويعتبر العلاج باللعب therapy التعبير عن المشاعر بصورة عفوية خاصة مع حالات اضطرابات النطق والكلام او اضطرابات

\section{http://dx.doi.org/10.29009/ijres.3.2.2}


التواصل مع الاخرين. ونصح التربويون بضرورة الاعتماد علن الأنشطة الخفية المتضمنة في

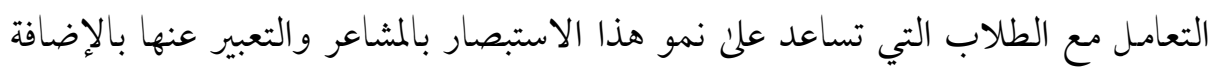

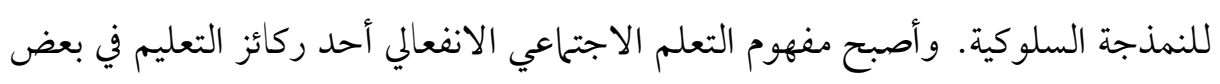
الدول مثل إنجلتر اللأطفال بين 4-10 سنوات من خلال المكونات الخمس الرئيسة له: إدر اك اك الذات self-awareness، إدارة الانفعالات managing feelings، الدافعية motivation المشاركة الوجدانية social skills ولم. والمهارات الاجتماعية

Scott \& Barrett وثمة فائدة جديدة لمفهوم التعلم الانفعالي - الاجتماعي حيث أوضح

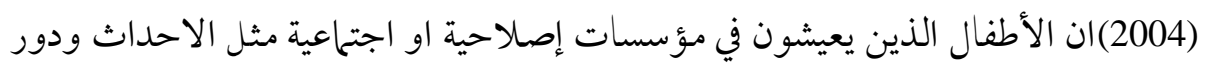

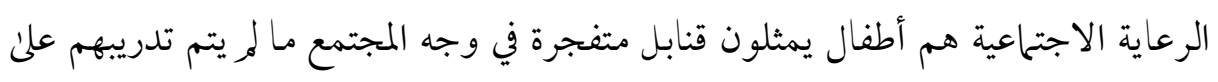

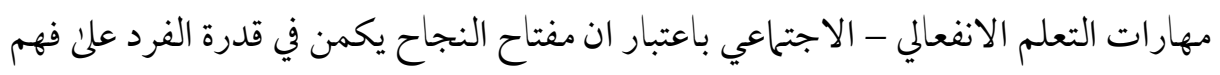

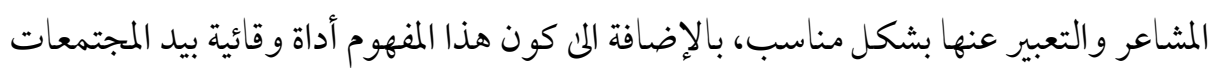

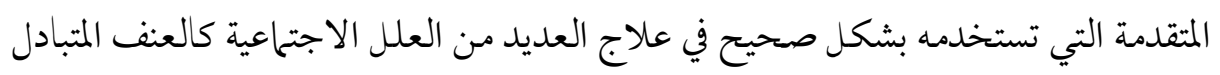

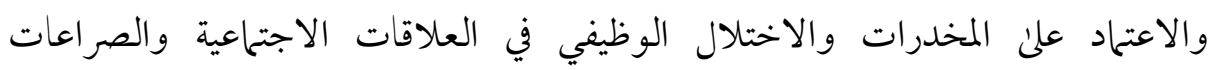
الاجتماعية(p.9). وتعلق (Garcia,2015,13) بان تطبيق مفهوم التعلم الانفعالي - الاجتماعي وني قد يكون مساهم رئيس في تصحيح مسار نتائج الطلاب الضارة وسلوكياتهم غير المواتية في ان لنان واحد.

وتشير (Pikul,2015,1) ان مسؤولية المعلم داخل الصف تتزايد في تعقيداتها من حيث ما هو مطلوب منه نتيجة لما حدث من تغيير في المجتمعات خلال العقدين الأخيرين حيث

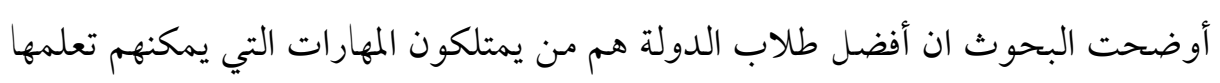


بجانب المعايير الاكاديمية التي يحصلون عليها، فلم تعد تغذية العقل وحدها كافية لتحقيق النجاح.

ويوضح (Zins \& Elias, 2006) ان التعلم القائم على اكساب المتعلم مهارات انفعالية اجتماعية سوف يقود بالمتعلم النى إدارة وضبط انفعالاته، ابتكار حلول لمشكلاته، ونجاحه في إقامة علاقات شخصية ناجحة مع الاخرين، وأطلق عليها برنامج التعلم الانفعلي الاجتماعي Social-Emotional Learning (SEL) program. ولعل هذا يؤكد ما توصل اليه من سبقوهم (Stern, 2000,1) التي نادت بان من مهارات التعلم الاجتماعي الانفعالي صقل الذكاء الانفعالي للفرد لوضعه الحالي وللمستقبل، كما ان تضمين استراتيجيات التدريس مهارات SEL سوف يساعد الطلاب كثير في التركيز فيما يدرسونه بالإضافة المى الاثار الجانبية الإيجابية في المنافسة علني مراكز متقدمة في الاقتصاد العالمي والبنية الصحية للفرد وتقليل فرص الفشل قدر الإمكان في الابتعاد عن المخدرات .(Elias,O’Brien \& Weissberg,2006,1)

وتشير اسماعيل (289:2017) ان اليقظة العقلية Mindfulness على قدر عال من الأهمية في حياتنا سواء في احداثها اليومية او المستقبلية واعتبرتها عنصرا من عناصر الصحة النفسية بحا اوضحته نتائج البحوث من علاقات إيجابية بين اليقظة العقلية والاستقرار النفسي، وتقدير الذات، والرضاعن الحياة.

وتري عبد الله (2013: 343) ان اليقظة الذهنية توسع من رؤية الفردو وادر اكاته بها يزيد من فرص النجاح، ووفق ما أظهرته نتائج الدراسات ان الافر اد اليقظين عقليا يظهرون انتباها أكثر ورغبة اقوى في انجاز المهام بالإضافة لتحسن الذاكرة لديهم ويصبحون أكثر ابداعا واقل

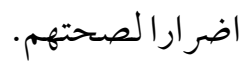


وتشير السقا (272:2016) ان حالة الفرد الشعورية للجوانب المعرفية والأفكار الني بداخله والتي تساعده علن التفكير التو افقي، كما تقتضي وجود عو امل معرفية ووجدانية وحالة

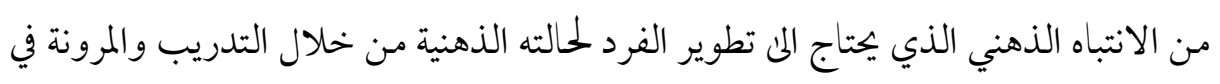
القدرة علن التفكير والتأمل في ردود الأفعال المعتادة والقدرة علني استبدال غير المناسب بأفكار

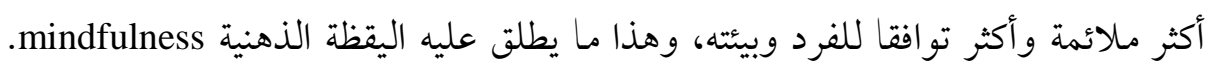
ويتمتع الافراد من ذوي اليقظة الذهنية المرتفعة بتوافق نفسي اجتماعي علاي بالإضافة لمستون

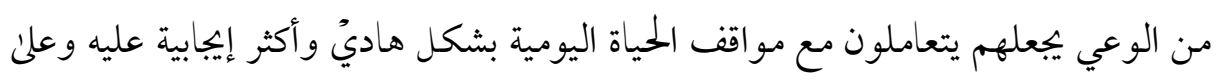

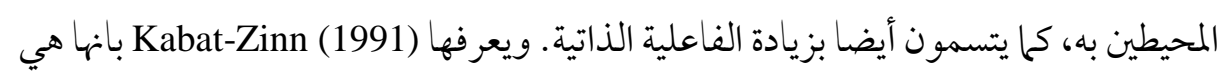
التي تلقي الضوء بصورة نوعية علن الغرضية في اللحظة الانية والتي لا يمكن الحكم عليها .nonjudgmentally

ويرن Naik, Harris, and Forthun (2013) أن الأصل في الكلمة هي كلمة

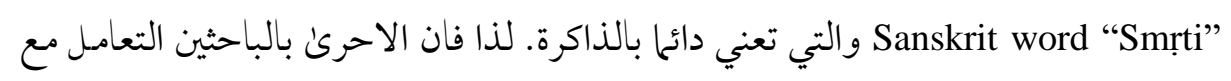

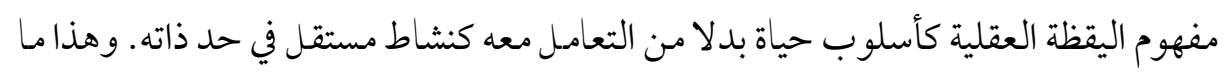
ذهب اليه (Black,2011) ان اليقظة العقلية تعني ان نتذكر الاهتحام المطلوب لحنبراتنا الانية. وتتفق الدراسات في العقد الأخير ان اليقظة العقلية تتكون من ثلاث ابعاد: الغرض

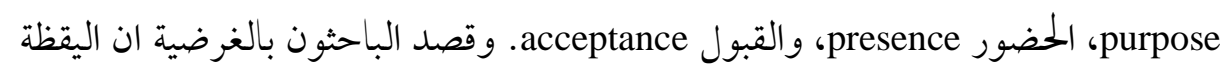

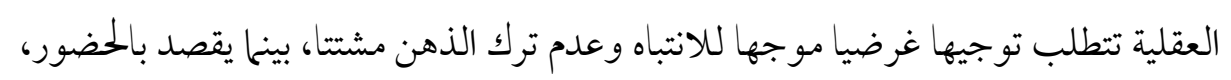

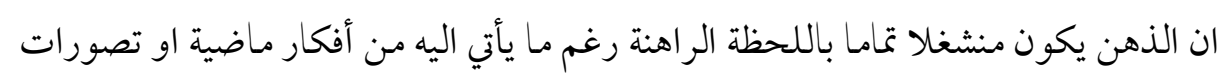

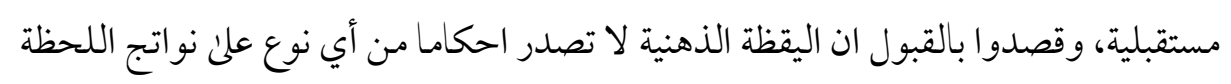


الر اهنة بكل ما تحتويه من مشاعر واحاسيس وانفعالات ولكنها تراقب النواتج حتى ينتهي الحدث (Naik, Harris, Forthun, 2013).

وتعد كلمة المرونة resilience مشتقة من الأصل اللاتيني resiliens والتي تعني القفز مرة اخرى مump back، او الارتداد bounce back، او التراجع fall back، وهي مشتقة من

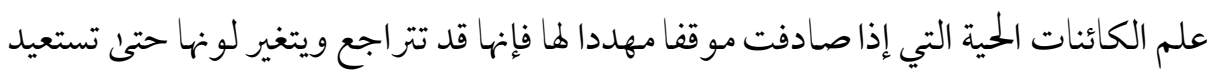

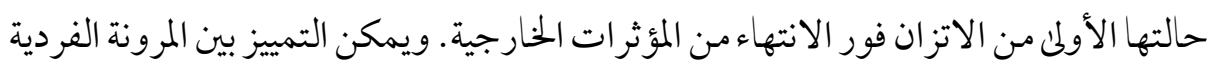
- الجمعية team-individual resilience حيث تعنئ المرونة الفردية قدرة الفرد علن الاستجابة للمخاطر، بينما المرونة الجمعية فهي التي تنشأ لدن مؤسسة او منظمة حيث تتكون لدني أعضاؤها بمرور الوقت بهدف إنجاح رسالتها وتحقيق أهدافها .Gonzalez, et al, 2018,1) وتعرف جمعية علم النفس الامريكية للأمر اض النفسية (APA,2008) المرونة النفسية

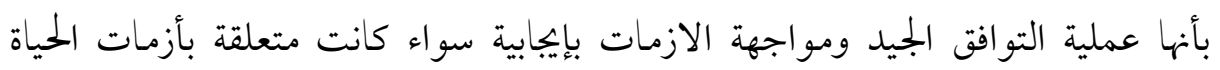
الاقتصادية او المتعلقة بفشل العلاقات مع الاخرين او حتى المرتبطة بالأزمات الصحية. ويرئ (Hart \& Sasso,2011) النفس المعاصر خاصة ميدان علم النفس الإيجابي التطبيقي. وترى (Conner and Davidson,2003) ان المرونة تثثل جملة الصفات الشخصية التي تككن الفردمن مو اجهة الازمات والشدائد. كما توضح ان البحوث علنم مدار العقدين الأخيرين

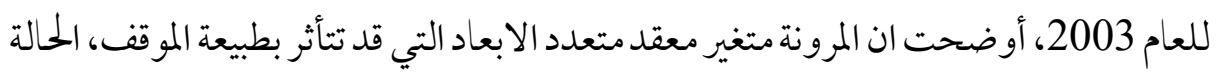

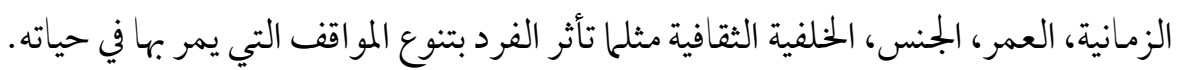
وتذكر بوسعيد (2014: 12) ان المرونة هي الحد الفاصل بين الثبات المطلق الذي يصل

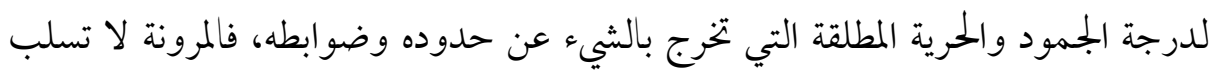


التماسك ولا هي ثبات يمنع الحركة. كما يلاحظ انها التوسط والقابلية للتغيير والاخذ بأيسر الحلول. كما تذكر أيضا تعريفا للمرونة النفسية بأنها عملية التوافت الجيد والمواجهة الإيجابية للشدائد والصدمات كالعلاقات الاسرية والعلاقات مع الاخرين والمشكلات الصحية الخطيرة وضغوط العمل (ص13). ويرى (Michel,2010,9) ان المرونة resilience هي القدرة على الاستمرار في التركيز علن اللحظة الر اهنة دون الاستعر اض لأفكار سلبية او تشتيت او انسحاب. ego ويرتبط بمفهوم المرونة بعدد من المفاهيم الأخرى' في علم النفس مثل: قوة الانا strength مرونة الانا، المناعة النفسية، التفكير الإيجابي، الهدوء الانفعالي، الاتزان الانفعالي، التو افت الإيجابي، والقدرة علن التكيف (بوسعيد، 2014، 13-15). كما ان لأصحاب المرونة النفسية بجموعة من السمات يمكن اجماها في: الإيجابية والتكيف في الظروف المعاكسة، القدرة علن تحمل الإحباط، التفاؤل، تنوع استخدام الأساليب المعرفية، القدرة علن ضبط النفس، العمل بفاعلية وفق منظومة من القيم المحددة للشخصية.

ويذكر ان المرونة تتأثر بدرجة اتصال الفرد باللحظة الراهنة من خلال الاستبصار، تقبل الذات، القدرة على ترويض الانفعالات القوية، إدارة الذات، منظومة القيم التي تحكم الشخصية، والالتزام في العمل)(Ciarrochi, Bilich, \& Godsell, 2010) . ويقول الضامن وسمور (2017: 172) ان المرونة النفسية تعد الركيزة الأساسية لصحة الفرد النفسية حيث تمثل له القوة الدافعة لمواجهة الاحداث اليومية الضاغطة بها يولد لديه الإحساس بالرضا والهدوء والاستقرار والاتزان من خلال التحكم في المشاعر والانفعالات والتعبير عنها بصورة إيجابية. 
وتوضح دراسة (Christine,\&Kathleen, 2012) ان الانفعالات والأفكار الإيجابية

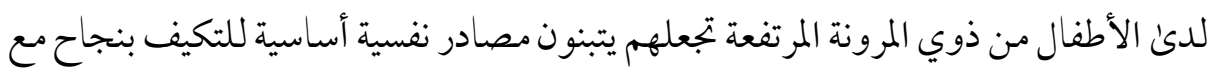
الازمات والضغوط ممايجعلنا ننظر للانفعالات والأفكار الإييابية انها مصدر وقائي جيد لتقليل أثار سلبية شديدة ناجمة عن الضغوط النفسية.

ويعتقد (Cohen,2018) ان كل منا يستطيع تعلم المرونة النفسية تماما كما يتعلم اية مهارة

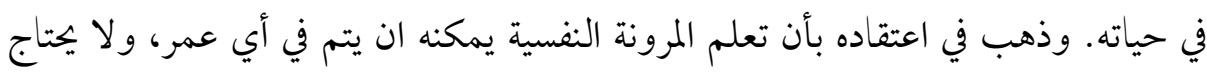

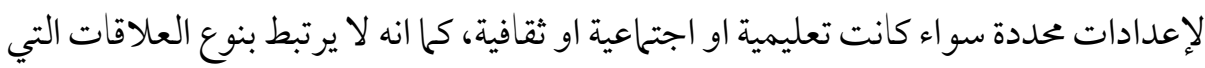
تحدد سلو كياتنا مع الاخرين، وكل ما نحتاجه فقط هو الإرادة نحو تحقيقها ثم السير قدما في تئي

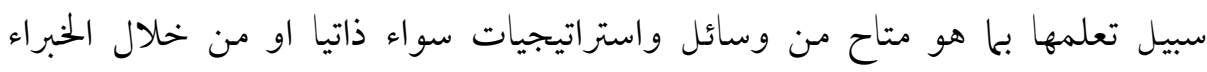

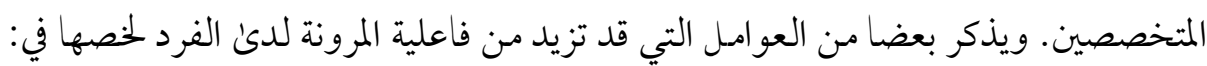

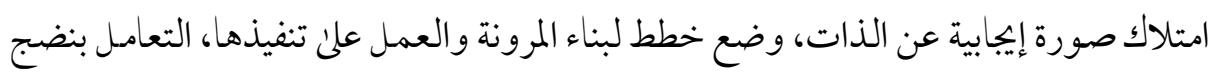
وواقعية مع المشاعر، امتلاك مهارات جيدة للتواصل مع الاخرين، وأخيرا امتلاك درجات عالية من مهار ات حل المشكلات.

ويعد مصطلح المرونة النفسية من المصطلحات الهامة في مجال علم النفس والصحة النفسية لارتباطه الوثيق بالتوافق النفسي والقدرة علن الحفاظ علن مستوى مستقر من الثبات

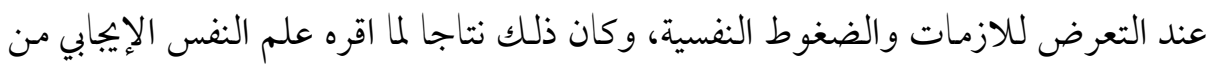

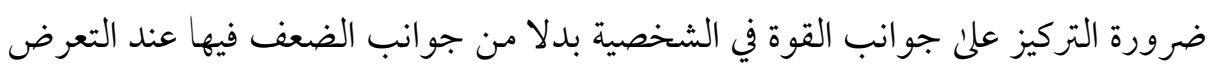
للازمات والشدائد (أبو زيد، عرودئ 2017، 230).

وذكر (Keye \& Pidgeon, 2013) أن المرونة النفسية هي في الواقع قدرة الفرد علن التعامل بنجاح مع المو اقف الضاغطة بهدف الوصول لحالة من التو افق النفسي حاليا ومستقبلا. 
وعلي التوازي مع أبحاثMaslach عام 1982، فقد ظهر مفهوم العاطفة كذكاء محدد ومستقل في اعمال Peter Salovey John Mayer عامي 1990، 1993 حيث قدما مفهوما وتصورا جديدا للذكاء اطلقا عليه الذكاء الانفعالي Emotional Intelligence ليشيرا به لقدرة الفرد علي تنظيم وتوظيف انفعالاته لخدمة التفكير وحل المشكلات لتحقيق نوعا جديدا من النمو هو النمو الانفعالي المعرفي (Mayer , Caruso \& Salovey , 1997:267)، وقد دع) فكرتها هذه بأن الذكاء الانفعالي يعزز المنطق الذي يفترض أن القدرات المعرفية تعمل من خلال عمليات انفعاليه ووجدانيه وأن المعلومات الانفعالية مكون اساسي في القدرة علي حل المشكلات.

وعلي الرغم من ابحاث Thorndike عام 1921، Guilford عام 1956، Gardener عام 1983 في مجال الذكاء الاجتماعي التي مست أهمية الانفعالات في وظائف العقل، الا أن الذكاء الانفعالي لم يظهر في الادب السيكولوجي الا علي يد كل من Mayer \& Salovey عام 1990، وبعدها انتشر صيته في كتاب Daniel Goleman عام 1995 الذي حقق افضل المبيعات بعنوان "الذكاء الانفعالي"، وفي عام 1997 ظهر بار - اون Bar-On، اول من ادخل مفهوم نسبة الذكاء الانفعالي (EQ) Emotional Quotient (Nancy , 2009,1)، حيث انتشر كمتغير في الدراسات التربوية ليرتبط بمتغيرات مثل تعزيز الأداء الوظيفي للفرد، النجاح في

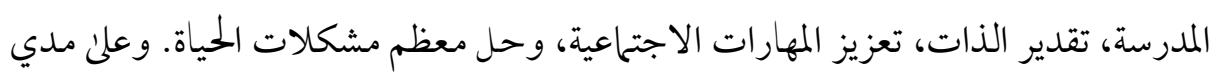
العقدين الأخيرين، برز مفهوم الذكاء الانفعالي في الدراسات السيكولوجية الفارقة Differential Psychology

.(Carter , 2009 ,2) 
تقول (Nancy , 2009,5) نقلا عن Goleman عام 1995 أن الذكاء الانفعالي يمكنه أن يساهم بدرجة كبيرة في نو اتج حياتيه علي قدر عال من الأهمية بالنسبة للفرد تتمثل في تحسين التعلم، خفض العدوانية، تحسين القدرة على اتخاذ القرار، بعض المتغيرات المرتبطة بالنجاح في الحياة، حتى أنه ذهب لأعمق من ذلك أن الذكاء الانفعلي يعادل في أهميته ثلاثة اضعاف المهارات التكنولو جية المتقدمة وأكثر اهمية من الذكاء بنسبته المعروفة (IQ) للنجاح الوظيفي في اي مستوي.

وبدأ التأصيل لهذا المفهوم من خلال كتابات Thorndike عام 1937 الذي اعتبر أن الذكاء لابد أن يتضمن العمليات الانفعالية مقرونا ومدعوما بالقدرات الذاتية لدي الفرد ليؤدي وظيفته في المواقف ذات التعامل مع الأخرين، وفي عام 1950 اقترح David Wechsler

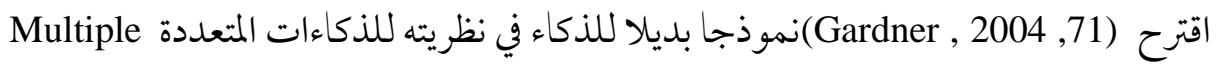
حيث عرف فيه الذكاء بأنه بجموعة القدرات التي تسمح للفرد بحل Intelligence Theory مشكلاته، وبذلك نجد انه قد غير قو اعدلعبة الذكاء من كونه معتمدا فقط علن القدرات العقلية ليشمل ابعادا اخري يمكن بناؤها في سبعة انواع من الذكاءات هي: الذكاء اللغوي، الذكاء المنطقي الرياضي، الذكاء الموسيقي، الذكاء الجسمي الرياضي، الذكاء المكاني، الذكاء البين شخصي (الاجتتاعي)، و الذكاء الشخصي. وتشير (Robitailla,2008,2) أن العقود الأخيرة كانت شاهدة علي عودة التحدي لمفهوم الذكاء واعتباره سمه وحدويه Initary traitتشير للقدرات العقلية والانفعالية حيث أن الذكاء هو محصله النمو الإنساني عن كونه قدره عقليه مستقله تم الوصول اليها اساسا بعامل الوراثة. 
وقد تساءل الباحثون حول ما يقيسه الذكاء الانفعالي هل هو بمثابة قدره قابلة للتحديد الكمي بمقاييس الأداء مثله في ذلك اختبارات الذكاء المألوفة، ام هو تفاعل بين قدرات بعضها معرفيه واخري غير معرفيه كسمات الشخصية، والأنشطة الاجتحاعية، والدافعية والتي يمكن قياسها باستجابة الفرد عليها من خلال التقرير الذاتي باستخدام اسلوب الورقة والقلم؟ (Matthews, et al., 2002) ؛ وقد اوضح (Bar-On, 1997) أن اساليب التو افق وما يرتبط بها من اساليب إدارة الأزمات هي في الحقيقة مكونات رئيسه للذكاء الانفعالي. وتشير (2003, Kiani) أن الانفعالات تلعب دورا حيويا في إدارة الأزمات، بها ارتبطت به مع مكونات ايجابيه لإدارة الازمات مثل القدرة على التفاوض واستر اتيجيتها المؤثرة، حتى أن (Watkin,2000; Mayer et al , 2001) اعتبرو الذكاء الانفعلي أحد المفاتيح الهامة المحددة للأداء في بجال العمل لما يتضمنه من الجمع بين الذكاء العادي وسمات الشخصية. فالأداء الوظيفي يتطلب نجاح علي مستوي العلاقات البين شخصيه، والقدرة علن التو ائم، والقدرة في العمل كفريق، حتى أن الكثير يعتبرون الذكاء الانفعالي حجر الأساس الذي تبني عليه سلو كيات التفاعل بين الشخصي (Goleman,1998). ويذكر أيضا ان Goleman قال انه عندما عمل علن مفهوم الذكاء الانفعالي عام 1998، قصد به كيف يصل الفرد بإمكاناته لدرجة التمكن من إدراك ذاته، إدارة انفعالاته، الادر اك الاجتحاعي وأخيرا، إدارة العلاقات الاجتماعية لتحقيق النجاح المهني بحياته.

ويقترح (Fisher ,Kret \& Broekens, 2018,1) ان أكثر مكونات الذكاء الانفعالي

أهمية هو مدىل ما يمكن أن يدركه الفرد من مشاعر على وجوه الاخرين، فقر اءة المعلومات لما يدور بذهن الاخر من أفكار وما يشعر به من أحاسيس ونو ايا علن قدر من الأهمية في التفاعلات الاجتماعية بين الافر اد، وبينت نتائج البحوث ان النساء اعلن من الذكور في هذه المهارات. 
وقد يتأثر الذكاء الانفعالي بعامل الجنس، فالذكور لهم أنماط من الذكاء الانفعالي مختلفة عنها لدي الإناث، ويؤكد ذلك انخفاضهم الملحوظ عن الرجال في المكونات الشخصية الخارجية (ادارة انفعالات الفرد ذاته)، و المكونات الشخصية الداخلية (التحكم في التعبير) (Reiff, Hatzes , Bramel \& Gibbon,2001) ويو ضح الذكاء الانفعالي أن ثمة ارتباطا عكسيا قويا بينه وبين ما يعانيه الفرد من صحة نفسية وبدنية سيئة، فالأفراد ذوي الذكاء الانفعالي المرتفع لديهم صحة نفسية وبدنية جيدة (Nancy , 2009,6) وهي بذلك تتفق مع (Sue-Chan \& Latham, 2004) أن البحث في بجال العلاقة بين الذكاء الوجداني والأداء الوظيفي اوضح أن التأثير بينها ايجبي بدلاله إحصائية، فهو يمكنه التنبؤ بأداء الطلاب في مرحلة البكالوريوس، كما يمكنه التنبؤ بالأداء داخل غرفة الفصل للمعلمين ومشرفيهم. ومما سبق يتضح ان متغيرات الدراسة الحالية: التعلم الانفعالي - الاجتماعي، اليقظة العقلية والمرونة النفسية والذكاء الانفعالي تتداخل في معانيها كقدرة لدى الفرد في التعامل مع المو اقف الضاغطة و الأزمات والشدائد وإنتاج أفكار جديدة للتكيف معها الان ومستقبلا. لذا، يمكن اعتبار التعلم الانفعالي - الاجتماعي المحرك الرئيس في اليقظة العقلية لدى الفرد والمرونة النفسية والذكاء الانفعالي لديه ومـا يحاول ان يصل اليه في المو اقف المختلفة؛ كما ان هذه المتغيرات تؤثر كل منها على الاخر في تكوين التعلم الانفعالي - الاجتماعي لدئ الفرد. 


\section{مشكلة الدراسة}

في الآونة الاخيرة نجد أن المجتمعات المختلفة تشهد موجات عارمة من العنف وعدم التحكم في الانفعالات وعلى الطلاب المعلمين في هذه المجتمعات أعباء ومسئوليات متز ايدة في تعقيداتها كونهم أفر اد يعيشون في هذه المجتمعات وكونهم معلمي المستقبل يتعاملون فيها بعد مع مئات الطلاب التي تعيش وتتأثر بها يحدث في المجتمع من حولهم من انفعالات وسلوكيات غير سوية ؛ ولذا فالتعلم القائم علن اكساب المتعلم مهارات انفعالية اجتماعية سوف يقود بالمتعلم الما إدارة وضبط انفعالاته، ابتكار حلول لمشكلاته، ونجاحه في إقامة علاقات شخصية ناجحة مع الاخرين؛ ونحن في امس الحاجة لذلك ليس فقط للطلاب في خختلف المراحل التعلمية ولكن في بداية الامر لمعلميهم وقدوتهم لتصحيح مسار نتائج الطلاب الضارة وسلو كياتهم غير المو اتية في ان واحد ومن ثم تنطلق مشكلة الدراسة الحالية من محاولتها التعرف علن قدرة كل من اليقظة العقلية والمرونة النفسية والذكاء الانفعالي في التنبؤ بالتعلم الانفعالي الاجتماعي لدىن عينة من الطلاب المعلمين بكلية التربية جامعة المنوفية من خلال التساؤلات التالية:

1. ما العلاقة بين التعلم الانفعالي الاجتماعي وكل من اليقظة العقلية والمرونة النفسية

$$
\text { والذكاء الانفعالي لدئ عينة من الطلاب المعلمين بكلية التربية؟ }
$$

2. هل يمكن التنبؤ بالتعلم الانفعالي الاجتماعي من المتغيرات: اليقظة العقلية والمرونة

النفسية والذكاء الانفعالي لدى' عينة من الطلاب المعلمين بكلية التربية؟

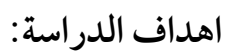

1. الكشف عن العلاقة بين التعلم الانفعالي الاجتماعي وكل من اليقظة العقلية والمرونة النفسية والذكاء الانفعالي لدى' عينة من الطلاب المعلمين بكلية التربية. 
2. التنبؤ بالتعلم الانفعالي الاجتحاعي من المتغيرات: اليقظة العقلية والمرونة النفسية والذكاء الانفعالي لدىن عينة من الطلاب المعلمين بكلية التربية.

- الأهمية النظرية: تأتي الأهمية النظرية للدراسة الحالية من أهمية الهدف منها ومتغيراتها وهو التعرف علن قدرة كل من اليقظة العقلية والمرونة النفسية والذكاء الانفعالي في التنبؤ بالتعلم الانفعالي الاجتماعي لدئ عينة من الطلاب المعلمين بكلية التربية جامعة المنوفية. وتأتي أهمية هذه الدراسة من كونها لم تختبر من قبل في حدود علم الدراسة

$$
\text { الحالية في ضوء ما أتيح هلا الاطلاع عليه. }
$$

الاجتماعي واليقظة العقلية، والمرونة النفسية، والذكاء الانفعالي لدى الطلاب المعلمين، سوف يتضح أهمية كل منها في التأثير بالأخر مما سيكون له جوانب تطبيقية

$$
\text { مستقبلا في البحوث المرتبطة بهذه المتغيرات. }
$$
تحديد المصطلحات:

$$
\text { - }
$$

ويقصد به حالة ذاتية شاملة تتضمن الإحساس بالطاقة، والثقة بالنفس، والاستمتاع، و السعادة و الهدوء، و العطاء، جميعها في حالة مترابطة ومتوازنة (Zhou and Ee Jessie,2012). ويعرف اجر ائيا بالدرجة التي يجصل عليها المفحوص من خلال تطبيق مقياس التعلم الانفعالي - الاجتماعي اعداد (Pikul, 2015) تعريب الدراسة الحالية.

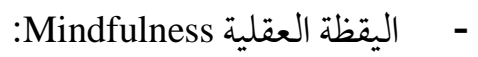


تتكون اليقظة العقلية من ثلاث ابعاد: الغرض purpose، الحضور presence، والقبول acceptance للانتباه وعدم ترك الذهن مشتتا، بينما يقصد بالحضور، ان الذهن يكون منشغلا تماما باللحظة الراهنة رغم ما يأتي اليه من أفكار ماضية او تصورات مستقبلية، وقصدوا بالقبول ان اليقظة الذهنية لا تصدر احكاما من أي نوع علن نواتج اللحظة الراهنة بكل مـا تحتويه من مشاعر واحاسيس وانفعالات ولكنها تراقب النواتج حتى ينتهي الحدث ( Naik, Harris,\&)

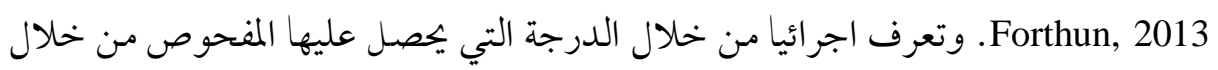
تطبيق مقياس اليقظة العقلية اعداد (Baer,2011) وتعريب الدراسة الحالية. - مesiliency المرونة النفسية وتعرف بأنها عملية التوافق الجيد ومواجهة الازمات بإيجابية سواء كانت متعلقة بأزمات الحياة الاقتصادية او المتعلقة بفشل العلاقات مع الاخرين او حتى المرتبطة بالأزمات الصحية. وتعرف اجرائيا من خلال الدرجة التي يجصل عليها المفحوص من تطبيق مقياس المرونة النفسية اعداد -THE CONNOR-DAVIDSON RESILIENCE SCALE (CD RISC,2003) ويقصد به القدرة علن الإدراك، و التقييم، والتعبير عن المشاعر؛ القدرة علن الوصول و

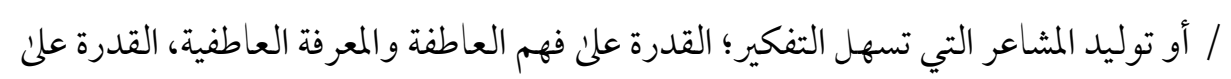
تنظيم العواطف للتعزيز العاطفي والنمو الفكري. ويعرف اجرائيا من خلال الدرجة التي يكصل عليها المفحوص من تطبيق مقياس الذكاء الانفعالي اعداد (شعيب، 2013). 
- الفرض الأول: توجد علاقة ارتباطية ذات دلالة إحصائية بين التعلم الانفعالي الاجتماعي وكل من الذكاء الانفعالي، المرونة النفسية، اليقظة العقلية لدى الطلاب المعلمين بكلية التربية جامعة المنوفية. - الفرض الثاني: تساهم المتغيرات المستقلة الذكاء الانفعالي، المرونة النفسية، اليقظة العقلية في التنبؤ بالتعلم الانفعالي الاجتهاعي لدى الطلاب المعلمين بكلية التربية جامعة المنوفية.

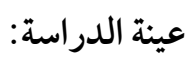
اعتمدت الدراسة الحلالية على عينة من طلاب الدبلوم العام الملتحقين ببرنامجج الدراسات العليا للعام الجامعي 2018/ 2019 بلغ قو امها 286 فرد بمتوسط عمر زمني 25.3 عام وانحر اف معياري 5.012. و اشتملت العينة على 254 من الاناث، 28 من الذكور.

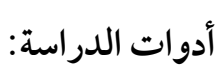

1. مقياس التعلم الانفعالي - الاجتماعي إعداد (Zhou and Ee Jessie,2012 ) وتعريب

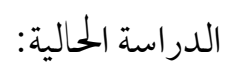

بعد استقر اء الدراسات التي اعتمدت علنى متغير التعلم الانفعالي الاجتماعي، لاحظت الدر اسة الحالية ان (Pikul, 2015) قد اعتمد في قياسه لهذا المتغير على نسخة متاحة على الانترنت في حين ان (Zhou and Jessie Ee,2012) قد اعد نفس الابعاد و العبار ات لنفس الأداة لقياس المنافسة الانفعالية الاجتماعية Social emotional competence questionnaire، وحدد الأخير معايير الثبات والصدق للأداة من خلال التحليل العاملي التوكيدي متوصلا للأبعاد الخمسة المكونة للتعلم الاجتماعي الانفعالي: ادراك الذات، إدارة الذات، الادراك الاجتماعي، 
مهارات العلاقات الاجتماعية، مهارة اتخاذ القرار المسئول. واتفق الباحثان أيضا في تعريفها

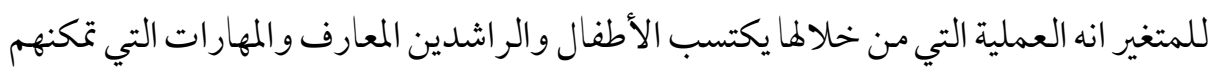
من التصرف بفاعلية عالية خلال المواقف التي نتعرض فيها للازمات والشدائد. ويتكون

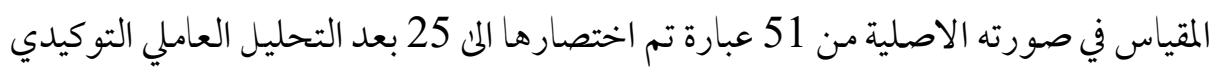

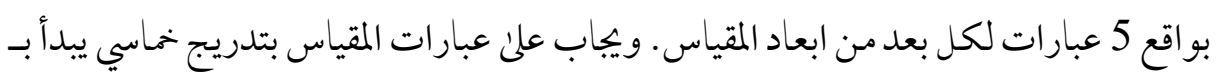

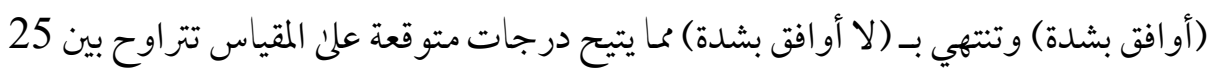

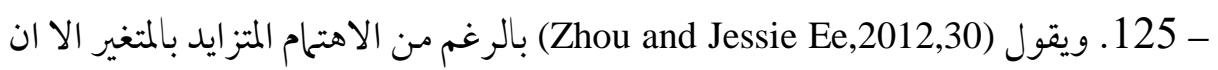
الاهتحام ببناء وتطوير أدوات لقياسه لم يكن بنفس الوتيرة خلال العقدين الأخيرين، الا ان

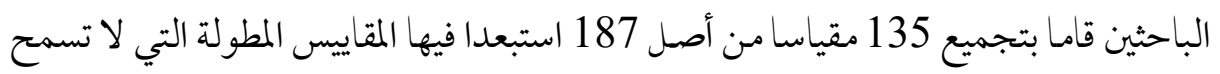
للطلاب باستكملها بالإضافة لاستبعاد المقاييس التي كانت تركز علن بعد واحد فقط من ابعاد المتغير . ثم تم استبعاد 40 مقياس من أصل 52 بسبب عدم الاعتماد عليها في الدراسات السابقة.

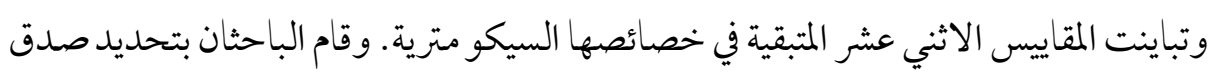

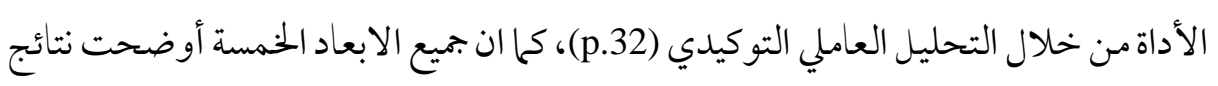
مقبولة في التناسق الداخلي والفا كرونباك التي تراوحت قيمه من 0.62 - 0.72

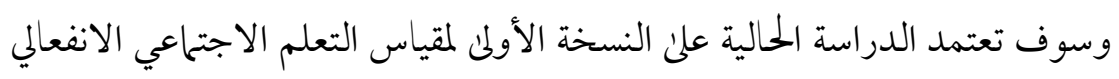
(52 عبارة) في الابعاد الخمسة المكونة له كدرجة كلية للتحقق من اهداف الدراسة. وقامت لدأل

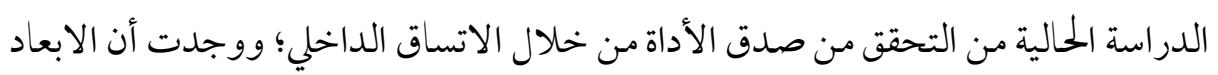

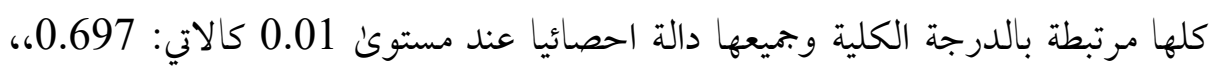
0.707، 0.736، 0.685، وتم التحقق من ثبات الأداة باستخدام الفا كرونباك والتجزئة

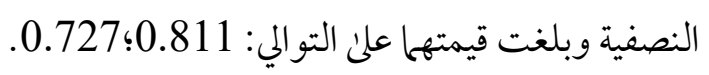


2. مقياس الأوجه الخمسة لليقظة العقلية Five Facet Mindfulness Questionnaire (BFMQ)

شرحت Ruth Baer عام 2011 أسلوب بناء اداتها التي استخدمت في الكثير من الدراسات المتعلقة باليقظة العقلية. حيث قامت الباحثة ببناء مقياسها من خلال استعراضها لمقاييس اليقظة العقلية الموجودة بالميدان وعددها خمسة استبيانات شهيرة وهي: The) (The الذي يتكون من 30 مفردة، مقياس Freiburg Mindfulness Inventory,2001) (The الذي يتكون من 15 مفردة، مقياس Mindful Attention Awareness Scale,2003) Kentucky Inventory of Mindfulness Skills,2004) (The Cognitive and Affective Mindfulness Scale-Revised,2007) 12 مفردة، ومقياس (The Southampton Mindfulness Questionnaire,2008) الذي يتكون من 16 مفردة. واظهرت الباحثة نقدها للمقاييس الخمسة ونهجت أسلوبا أخر في بناء مقياسها لليقظة العقلية، حيث قامت بتجميع العبارات في هذه المقاييس وبلغ عددها 112 مفردة وقامت بتحليلها عامليا من خلال دراستها علن عينات مختلفة من المستجبيين ووصلت لبناء مقياسها الذي يتكون من خمسة عوامل هي: عدم الاستجابة للخبرات الداخلية (عدم التفاعل nonreact)، الملاحظة/ الحضور/ الاحاسيس/ المفاهيم/ المشاعر (الملاحظة observe)، التعامل مع الوعي / التركيز (السلوك المدرك act aware )، (الوصف) describe)، و (عدم الحكم بناء عن الخبرة non judge). وتذكر (Bergomi et al , 2012) أن قياس اليقظة العقلية كان في حاجة ماسة لأسلوب مناسب وتم ذلك من اختبار FFMQ. وتستطرد أيضا، هذا المقياس يتصف بالشمولية والتكاملية لمفهوم اليقظة العقلية من خلال ما أفرزه التحليل العاملي لمكوناته الخمسة مـا يجعل بناؤه وتصميمه تجريبيا قبل أن يكون نظريا. و اتصف المقياس بقيم مرتفعة من الثبات والصدق، حيث أوضحت نتائج الارتباطات الداخلية قيا ذات دلالة 
إحصائية (Goldberg et al, 2015). ويتكون المقياس من 39 عبارة يجاب عنها بخمسة بدائل تبدأ من نادرا الما دائم) (1-5) منها 19 عبارة معكوسة (5-1) )، وبذلك تكون درجات المقياس متراوحة بين 38 - 190. وتدل الدرجة المرتفعة على وجود اليقظة العقلية. ويتم حساب قيمة الدرجة للفرد لكل بعد ومقارنتها بمتوسط الأداء في هذا البعد حتى يتسنى معرفة ان كان متوسطا في اداؤه علن اليقظة العقلية اعلن او اقل. كما يمكن التعامل مع المقياس أيضا في صورة درجة كلية لمجموع درجات المفحوص علن ابعاد المقياس. ويبين الجلدول التالي بيان بالأبعاد وعباراتها.

\begin{tabular}{|c|c|}
\hline العبارات التي تقيس البعد & 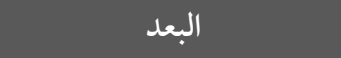 \\
\hline $1+6+11+15+20+26+31+36$ & observe الملاحظة \\
\hline $2+7+12 R+16 R+22 R+27+32+37$ & الوصف Describing \\
\hline $5 R+8 R+13 R+18 R+23 R+28 R+34 R+38 R$ & 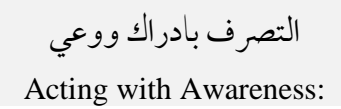 \\
\hline $3 R+10 R+14 R+17 R+25 R+30 R+35 R+39 R$ & عدم الحكىم Non judging \\
\hline $4+9+19+21+24+29+33$ & عدم التفاعل Non reactivity \\
\hline جموع الابعاد الخمسة & الدرجة الكلية لليقظة العقلية \\
\hline
\end{tabular}

تعني ان العبارة معكوسة في تصحيحها. وسوف يتم التعامل مع المقياس كدرجة كلية فقط للتحقق من اهداف الدراسة. وقامت الدراسة الحالية من التحقق من صدق الأداة من خلال الاتساق الداخلي؛ ووجدت أن الابعاد كلها مرتبطة بالدرجة الكلية وجميعها دالة احصائيا عند مستوى 0.01 جميع العبارات مرتبطة بدلالة إحصائية عند 0.01 ماعدا العبارات: 32،28،17،11، وتم حذفها، وتم التحقق من ثبات الأداة باستخدام الفا كرونباك والتجزئة النصفية وبلغت قيمتها على التوالي: 0.692،0.711 
3. مقياس المرونة النفسية THE CONNOR-DAVIDSON RESILIENCE SCALE (CD-RISC,2003) انطلقت Kathryn Conner عام 2003 في اعتقادها أن المرونة النفسية ترتبط بأساليب ونو اتج التعاملـ مع حالات القلق والاكتئاب والتعامـل مع الضغوط النفسية. وقام معدا المقياس بالاعتماد في صياغة مفردات المقياس مما قام به Kobasa عام 1979، في بعد الصلابة hardiness بها فيه من عبارات تعكس التحكم control، الالتزام commitment، و التغيير change. كما اعتمدت على ما قام به Rutter,1985 في تطوير استراتيجية ذات هدف واضح في توجيه الأداء، بناء تقدير ذات قوي مدعوما بثقة عالية في النفس، قدرة علن التكيف مع التغيير، مهارات حل المشكلة، روح الدعابة في مواجهة الاجهاد، تحمل المسؤولية في مواجهة الضغوط والشدائد، التدعيم الإيجابي، التجارب السابقة للنجاح والانجاز، وهاتين الأخيرتين تعكسان أساس مفهوم المرونة النفسية. ومن اعحال Lyons,1991 بعض المفردات التي تقيس الصبر والتحمل و القدرة على التعاملـ مع الضغوط و الأزمات والالام. ومن اعمال Shackleton دور الايـان باله كو احدة من العناصر الضرورية للمرونة النفسية وهو البعد الروحي. وقام الباحثان ببناء اداتها التي تكونت من 25 مفردة يجاب عنها بخمسة بدائل تبدأ بـ أبدا وتنتهي بـ دائما. وقام الباحثان بتصحيح المقياس بتدريج 0-4 الا ان الدراسة الحالية سوف تعتمد علن تدريج خماسي 1-5، ومن ثم فان درجات المقياس تتراوح بين 25-125 وتمثل الدرجة العليا على المقياس ارتفاعا في درجة المرونة النفسية عند الفرد. وسوف يتم التعامـل مع المقياس كدرجة كلية للتحقق من

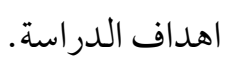
ثبات وصدق المقياس: قام الباحثان بحساب ثبات المقياس باستخدام أسلوب التطبيق وإعادة التطبيق (معامل الثبات 0.87)، وكذلك حساب قيم الفا كرونباك (0.89-0.70) بالإضافة المى الاعتحاد علن أساليب الارتباط بالمحكات الخارجية مثل الاختبارات التي الاقتباس 
عبار ات منها كتعبير عن الصدق (معاملات الارتباط تراوحت بين 0.30 - 0.70. كما أجري الباحثان تحليلا عامليا للمقياس منتجة خمسة عوامل: المنافسة، الثقة، تقبل إيبابي للتغيير، الضبط، والعامل الروحي. وقامت الدراسة الحالية من التحقق من صدق الأداة من خلال الاتساق الداخلي؛ ووجدت أن الابعاد كلها مرتبطة بالدرجة الكلية وجميعها دالة احصائيا عند مستوى 0.01 ماعدا العبارات:30،18،8،وتم حذفها، وتم التحقق من ثبات الأداة

باستخدام الفا كرونباك و التجزئة النصفية ويلغت قيمتها علن التو الي: 0.7800.785 وسوف يتم التعامل مع المرونة النفسية كدرجة كلية للتحقق من اهداف الدراسة.

$$
\text { 4. مقياس الذكاء الانفعالي: إعداد (شعيب،2012) }
$$

تكون مقياس الذكاء الانفعالي من 33 عبارة تدور حول المقصود بالذكاء الانفعالي بمجموعة المهار ات التي تؤثر جميعها في قدرة الفرد التعامل بنجاح مع مطالبه. ويتم الاجابة علن المقياس بطريقة ليكرت خماسية الاختيارات التي تبدأ بالمو افقة التامة على السلوك الذي تسأل عنه العبارة لتعبر عن أقصئ درجة لتواجد المهارة الانفعالية عنده، وتقدر بخمس درجات، وتنتهي باقلها وهي درجة واحدة يجيب عنها المفحوص بعدم الموافقة التامة، وهي تعبر عن أقل مستوي للمهارة التي يمكن تو اجدها لدي المفحوص، ومن ثم تتراوح درجات المقياس بين 33 لأقل مستوي ممكن من المهارات الانفعالية الناجحة، 165 لتمثل أقصى مستوي ممكن من الأداء يمكن الوصول اليه في هذه المهارات الانفعالية. وقامت الدراسة الحالية من التحقق من صدق الأداة من خلال الاتساق الداخلي؛ ووجدت أن الابعاد كلها مرتبطة بالدرجة الكلية وجميعها دالة احصائيا عند مستوى 0.01 جميع العبارات مرتبطة بدلالة إحصائية عند 0.01 ماعدا العبارة 28وتم حذفها، كما وجدت أن العبارات 12،5 دالة عند 0.05 وتم التحقق من ثبات الأداة باستخدام الفا كرونباك و التجزئة النصفية وبلغت قيمتها علنى التو الي: 0.677-0.614

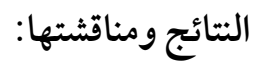


الفرض الأول: وقد تم اختبار الفرض الأول من خلال استخدام معامل الارتباط لبيرسون، وتم حساب معاملات الارتباط البينية للمقاييس الأربعة كدرجة كلية بعد حذف العبارات غير

$$
\text { المرتبطة، حيث كانت قيم معامل الارتباط كما هو موضح بالجمدول رقم (1) }
$$

جدول رقم (1) معاملات ارتباط بيرسون بين كل من التعلم الانفعلي - الاجتميع، اليقظة العقلية، المرونة النفسية، والذكاء الانفعلي

\begin{tabular}{|c|c|c|c|}
\hline الذكاء الانفعالي & المرونة الثفسية & اليقظة العقلية & المتغير \\
\hline *** 0.393 & $* * 0.611$ & $* * 0.3$ & التعلم الانفعالي - الاجتماعي \\
\hline
\end{tabular}

وتشير النتائج الموجودة بالجدول (1) المي وجود علاقة ارتباطية دالة احصائيا عند مستوى 0.01 بين كل من التعلم الانفعالي - الاجتماعي، اليقظة العقلية، المرونة النفسية، والذكاء الانفعلي لدى الطلاب المعلمون من كلية التربية جامعة المنوفية. حيث يتضح من الجحول ان التعلم الانفعلي - الاجتحاعي ارتبط إيجابيا مع كل من المرونة النفسية (611.) والذكاء الانفعالي (0.393) واليقظة العقلية (0.3) وجميعها دالة احصائيا عند 0.01 (عدد المفحوصين 286). الفرض الثاني: ولقد تم اختبار صحة الفرض الثاني باستخدام تحليل الانحدار الخطي step-wise regression analysis العقلية، والثاني بإدخال المرونة النفسية والذكاء الانفعالي، ويوضح الجمدول رقم (2) بيان بنتائج اختبار الفرض احصائيا 
جدول (2) نتائج تحليل الانحدار الخطي للتبؤ بالتعلم الانفعالي - الاجتماعي من المتغيرات اليقظة العقلية، المرونة النفسية، والذكاء الانفعالي

\begin{tabular}{|c|c|c|c|c|c|c|}
\hline الدلالة & قيمة ف & متوسط & درجات & المربعات & & النموذج \\
\hline \multirow{6}{*}{ دالة 0.01} & 27.809 & 6603.009 & 1 & 6603.009 & الانحدار & \multirow{4}{*}{1} \\
\hline & \multirow{5}{*}{69.849} & \multirow[t]{2}{*}{237.442} & 281 & 66721.260 & المتبقي & \\
\hline & & & 282 & 73324.269 & الكلي & \\
\hline & & 10483.361 & 3 & 31450.084 & الانحدار & \\
\hline & & 150.087 & 279 & 41874.184 & المتبقي & \multirow[t]{2}{*}{2} \\
\hline & & & 282 & 73324.269 & الكلي & \\
\hline
\end{tabular}

ويشير جدول ف ان المتغيرات: اليقظة العقلية، والذكاء الانفعالي، والمرونة النفسية تساهم في التنبؤ بالتعلم الانفعالي - الاجتماعي حيث كانت قيمة ف 69.849 وهي دالة احصائيا عند مستوى 0.01

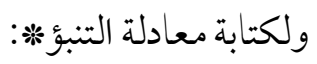

\begin{tabular}{|c|c|c|c|c|c|}
\hline الدلالة & ت & بيتا & & & النموذج \\
\hline .000 & 19.442 & 152.511 & 152.511 & الثابت & \multirow{2}{*}{1} \\
\hline .000 & 5.273 & .330 & & اليقظة العقلية & \\
\hline .000 & 5.373 & 55.899 & 55.899 & الثابت & \multirow{4}{*}{2} \\
\hline .002 & 3.115 & . 161 & & اليقظة العقلية & \\
\hline .000 & 10.061 & .835 & & المرونة النغسية & \\
\hline .000 & 4.102 & .277 & & الانفعالي & \\
\hline
\end{tabular}

http://dx.doi.org/10.29009/ijres.3.2.2 
التعلم الانفعلي - الاجتماعي = 55.899 + 0.161 اليقظة العقلية + 0.835 المرونة النفسية + 0.277 الذكاء الانفعالي وتشير المعادلة الما المساهمة النسبية لكل من المتغيرات اليقظة العقلية، والذكاء الانفعالي والمرونة النفسية يمكنها المساهمة بدلالة إحصائية في التنبؤ بالتعلم الانفعالي - الاجتماعي. ويمكن تفسير تلك النتائج فن ضوء مـا اشارت إلية الدراسات المرتبطة بهذه المتغيرات حيث أشارت دراسات ( عبد الله،2013)،( السقا،2016)، (إسماعيل،2017) إلى أن اليقظة الذهنية توسع من رؤية الفرد وادراكاته بها يزيد من فرص النجاح، فالافراد اليقظين عقليا يظهرون انتباها أكثر ورغبة اقوى في انجاز المهام بالإضافة لتحسن الذاكرة لديهم ؛ إضافة إلى أن حالة الفرد الشعورية للجوانب المعرفية والأفكار التي بداخله تساعده علن التفكير التو افقي، كما تقتضي وجود عوامل معرفية ووجدانية وحالة من الانتباه الذهني الذي يحتاج النى تطوير الفرد لحالته الذهنية من خلال التدريب والمرونة في القدرة على التفكير والتأمل في ردود الأفعال المعتادة والقدرة علن استبدال غير المناسب بأفكار أكثر ملائمة و أكثر توافقا للفرد وبيئته،ولهذا يتمتع الافراد من ذوي اليقظة الذهنية المرتفعة بتو افق نفسي اجتماعي عالي بالإضافة لمستوى من الوعي يجعلهم يتعاملون مع مواقف الحياة اليومية بشكل هاديٌ وأكثر إيجابية عليه وعلى لئ المحيطين به، كما يتسمون أيضا بزيادة الفاعلية الذاتية ويصبحون أكثر ابداعا واقل اضرارا

كما ان لأصحاب المرونة النفسية مجموعة من السمات يمكن اجماها في: الإيجابية والتكيف في الظروف المعاكسة، القدرة علن تحمل الإحباط، التفاؤل، تنوع استخدام الأساليب المعرفية، القدرة على ضبط النفس، العمل بفاعلية وفق منظومة من القيم المحددة للشخصية؛ فالمرونة 
النفسية تعد الركيزة الأساسية لصحة الفرد النفسية حيث تمثل له القوة الدافعة لمواجهة الاحداث اليومية الضاغطة بها يولد لديه الإحساس بالرضا والهدوء والاستقرار والاتزان من خلال التحكم في المشاعر والانفعالات والتعبير عنها بصورة إيجابية.وكل منا يستطيع تعلم المرونة النفسية تماما كما يتعلم اية مهارة في حياته. وكل ما نحتاجه فقط هو الإرادة نحو تحقيقها ثم السير قدما في سبيل تعلمها بها هو متاح من وسائل واستراتيجيات سواء ذاتيا او من خلال الخبراء المتخصصين؛ وهذا يتفق مع ما أوضحة (بوسعيد، 2014)، (Cohen,2018). ويساهم الذكاء الإنفعالى بدرجة كبيرة في نواتج حياتيه علي قدر عال من الأهمية بالنسبة للفرد تتمثل في تحسين التعلم، خفض العدوانية، تحسين القدرة علي اتحاذ القرار، بعض المتغيرات المرتبطة بالنجاح في الحياة، فأكثر مكونات الذكاء الانفعالي أهمية هو مدئ ما يمكن أن يدركه الفرد من مشاعر على وجوه الاخرين، فقراءة المعلومات لما يدور بذهن الاخر من أفكار وما يشعر به من أحاسيس ونوايا علن قدر من الأهمية في التفاعلات الاجتماعية بين الافراد وهذا (Fisher ,Kret ,\& Broekens, 2018)، ، يتفق مع مـا أوضحة (Nancy , 2009) ومن ثم ترى الدراسة الحالية وجود علاقة إرتباطية بين التعلم الإنفعالى - الإجتتاعى و اليقظه الذهنية والمرونة النفسية والذكاء الإنفعاله؛ وإنه يمكن التنبؤ بالتعلم الإنفعاله الإجتماعى من خلال اليقظه الذهنية والمرونة النفسية والذكاء الإنفعالن وهذا ما أوضحته نتائج

جدول (1) وجدول (2). 
1. إدراج التعلم الانفعالي الاجتهاعي ضمن كورسات كليات التربية بصفه خاصه والكليات الاخرى' بصفه عامه وذلك ووفقا للمعايير العالمية التي تنص علن أن " أفضل طلاب الدولة هم من يمتلكون المهارات التي يمكنهم تعلمها بجانب المعايير الاكاديمية التي يحصلون عليها، فلم تعد تغذية العقل وحدها كافية لتحقيق النجاح". 2. إدراج التعلم الانفعلي - الاجتحاعي كجزء خفي في المقررات الدراسية للطلاب العاديين بجانب تطبيقه علن الحالات ذوي الاحتياجات الخاصة من أجل التفاعل مجتمعيا و انفعاليا بصورة مناسبة. 3. استخدام التعلم الانفعالي - الاجتماعي كأداة وقائية بيد المجتمعات لعلاج العديد من العلل الاجتماعية بشكل صحيح كالعنف المتبادل والاعتماد علن المخدرات والاختلال الوظيفي في العلاقات الاجتماعية والصراعات الاجتماعية. 
1. أبو زيد، أحمد محمد (2017) . فاعلية برنامج ارشادي لتنمية الكفاءة الذاتية في تحسين المرونة النفسية لدئ التلاميذ ذوي صعوبات التعلم. مجلة التربية الخاصة بجامعة

$$
\text { الزقازيق، المجلد } 5 \text { (18)، 230-298. }
$$

2. احمد، هالة نجم الدين (2016). الذكاء الثلاثي الابعاد وعلاقته باليقظة العقلية لدئ طلبة الإعدادية. مجلة الأستاذ، ملحق العدد الحناص بالمؤتمر العلمي الرابع، 111-

3. إسماعيل، هالة خير (2017). المرونة النفسية وعلاقتها باليقظة العقلية لدن طلاب كلية

التربية: دراسة تنبؤيه. مجلة الارشاد النفسي جامعة عين شمس، المجلد 50 (1)،

$$
\text { .335-288 }
$$

4. الضامن، صلاح الدين وسمور، قاسم (2017). فاعلية برنامج ارشادي معرفي سلوكي

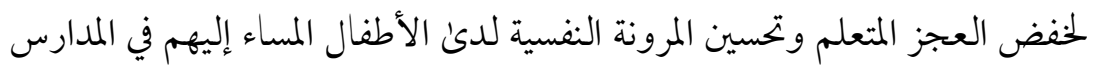

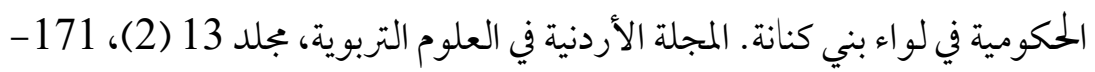

5. بوسعيد، سعاد (2014). المرونة النفسية وعلاقتها بقلق المستقبل لدئ النساء المصابات

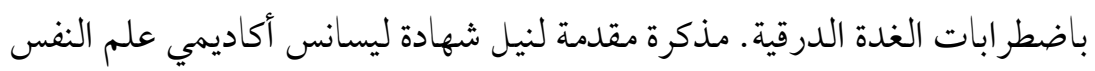
العيادي. الجزائر : جامعة قاصدي مرباح.

6. شعيب، علي محمود (2013). الضغوط النفسية والاحتراق النفسي والذكاء الانفعالي لدئ المعلمين والمعلمات ببرامج التربية الخاصة بمدينة نجران. بجلة دراسات نفسية

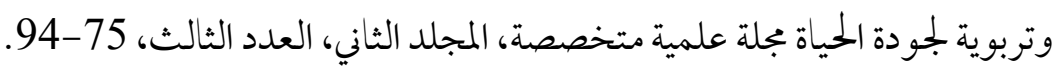


7. عبد الله، أحلام مهدي (2013). اليقظة الذهنية لدئ طلبة الجمامعة. بحث مستل من

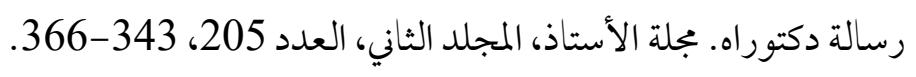

8. السقا، وردة عثمان (2016) . العلاقة بين اليقظة الذهنية وكلامن الغضب وادارته. بحث

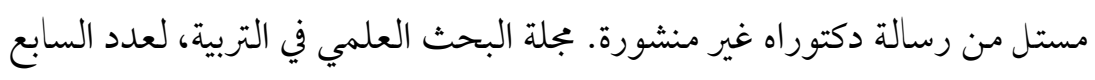

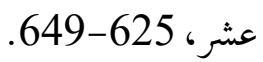




\section{References:}

- Abdullah, Ahlam Mahdi (2013). Mindfulness of the university students.

Research derived from a doctoral thesis. Journal of the Professor, Volume II, No. 205, 343-366. (In Arabic).

- $\quad$ Abu Zeid, Ahmad Mohammed (2017). The effectiveness of a counseling program to develop self-efficacy in improving the psychological resilience of students with learning disabilities. Journal of Special Education, Zagazig University, Vol. 5 (18), 230-298. (In Arabic).

- $\quad$ Ahmad, Hala Najmuddin (2016). Three - dimensional intelligence and its relationship to mental alertness among middle school students. Journal of the Professor, Supplement to the issue of the Fourth Scientific Conference, 111-136. (In Arabic).

- AL-Sakka, Warda Othman (2016). The relationship between mental alertness and both anger and management. Research drawn from an unpublished doctoral thesis. Journal of Scientific Research in Education, Number XVII, 625-649. (In Arabic).

- American Psychological Association (APA), (2008). Task force on Resilience and strength in Black children and Adolescents Resilience in African American children and adolescents; A vision for optimal development.

- $\quad$ Baer, R. (2011). Measuring mindfulness. Contemporary Buddhism, 12 (1), 241-261.

- $\quad$ Bar-On, R. (1997). The Emotional Quotient Inventory (EQ-i): A test of emotional intelligence. Toronto, Canada: Multi-Health Systems, Inc.

- $\quad$ Bergomi, C., Tschacher, W., \& Kupper, Z. (2012). The assessment of mindfulness with self-report measures: Existing scales and open 
issues.

Retrieved

from

https://link.springer.com/article/10.1007\%2Fs12671-012-0110-9

- Black, S. (2011). A brief definition of mindfulness. Mindfulness Research Guide. Retrieved from http://www.mindfulexperience.org

- $\quad$ Boussaid, Souad (2014). Psychological flexibility and its relationship to future anxiety in women with thyroid disorders. Note to obtain a Bachelor of Science in Clinical Psychology. Algeria: Kasidi Merbah University. (In Arabic).

- $\quad$ Carter, P. (2009). Assess your emotional intelligence with 22 personality $\begin{array}{llll}\text { questionnaires } \quad, \quad \text { Retrieved } & \text { from }\end{array}$ https://books.google.com.eg/books?id=QOSLIrMsxIQC\&printsec=fr ontcover\&hl=ar\&source=gbs_ge_summary_r\&cad=0\#v=onepage $\&$ $q \& f=f a l s e$

- Christine, A. \& Kathleen, A. (2012). The effectiveness of behavioral cognitive therapy on resilience among abused children. Psychotherapy, 19, 283-290.

- $\quad$ Ciarrochi., J, Bilich, L., \& Godsell, C. (2010).School of Psychology. University of Wollongong, New Harbinger Publications, Inc., Oakland, Australia.

- Cohen, H. (2017). What is Resilience?. Psych Central. Retrieved on October 19, 2018, from https://psychcentral.com/lib/what-isresilience/

- Conner, K. \&\& Davidson, J.(2003). Development of a new resilience scale: the Cooner-Davidson Resilience Scale (CD-RISC). DEPRESSION AND ANXIETY, 18,76-82. DOI: 10.1002/da.10113. 
- Connor,M.,\&Davidson,et.(2003).Development of a new resilience scale: The Connor-Davidson Resilience Scale (CD-RISC). Depression and Anxiety, 18, 76-82. https://doi.org/10.1002/da.10113

- Elias, M., O’Brien, M., \& Weissberg, R. (2006). Transformative leadership for social emotional learning. Student Services: National Association of School Psychologists. Retrieved from

- $\quad$ Elias, M., Zins, J., Weissberg, R., Frey, K., Greenberg, M., Haynes, N., Kessler, R., Schwab- Stone, M., \& Shriver, T. (1997) Promoting Social and Emotional Learning. Alexandria, Virginia: ASCD.

- $\quad$ Fisher, H.,Kret,E,\& Broekens, J. (2018). Gender differences in emotion perception and self - reported emotional intelligence: A test of the emotion sensitivity hypothesis. PLOS ONE,13 (1),1-19, https://doi.org/10.1371/journal.pone.0190712

- Garcia, H. (2015). An analysis of the impact of emotional literacy instruction on at-risk students. Unpublished Ph.D. Dissertation, Brandman University, California.

- Gardner, H. (2004). A multiplicity of intelligences: In tribute to Professor Luigi Vignolo. Available at: http://www.howardgardner.com/.../doc.../T101\%20A\%20Multiplicity \%20REVISED.pdf

- $\quad$ Gardner, H., Kornhaber, M., \& Wake, W. (1995) Intelligence: Multiple Perspectives. London: Harcourt Brace College Publishers.

- $\quad$ Goldberg, S.,Wielgosz, J., MacCoon, D., \& Rosenkranz, M. (2015). Does the five facet mindfulness questionnaire measure what we think it does? Construct validity evidence from an active controlled randomized clinical trial. Psychological Assessment, 10403590/15/\$12.00 http://dx.doi.org/10.1037/pas0000233 
- Goleman, D. (1998).Working with Emotional Intelligence. London: Bloomsbury.

- Gonzalez, B. et al. (2018).Development of the pilot resilience scale (employees, leaders and teams). Mental Health \& Human Resilience International Journal, 2(1), 1-7, DOI: 10.23880/mhrij-16000117.

- Hart, E., \& Sasso, T. (2011). Mapping the contours of contemporary positive psychology. Canadian Psychology/Psychologie canadienne, 52(2), 82-92. http://dx.doi.org/10.1037/a0023118

- https://sites.education.miami.edu/escresources/2014/12/03/transfor mative-leadership-for-social-emotional-learning-nationalassociation-of-school-psychologists/

- $\quad$ Ismail, Hala Khair (2017). Psychological flexibility and its relationship with mental alertness of students of the Faculty of Education: a predictive study. Journal of Psychological Counseling Ain Shams University, Volume 50 (1), 288-335. (In Arabic).

- Kabat-Zinn, J. (1991). Full catastrophe living: Using the wisdom of your body and mind to face stress, pain, and illness. New York: Delacorte

- $\quad$ Keye, D., \& Pidgeon, M. (2013). An Investigation of the Relationship between Resilience, Mindfulness, and Academic Self-Efficacy. Open Journal of Social Sciences, 1 (6), 1-4.

- Kiani, S. (2003). Emotional intelligence and conflict management in workplace. Unpublished thesis, National Institute of Psychology, Quaid-i-Azam University, Islamabad.

- Matthews, G., Zeidner, M., \& Roberts, D. (2002). Emotional intelligence: Science and myth. Cambridge, MA: MIT Press.

- $\quad$ Mayer, D., \& Salovey, P. (1997). What is emotional intelligence? In P. Salovey \& D. Sluyter (Eds.), Emotional development and emotional http://dx.doi.org/10.29009/ijres.3.2.2 
intelligence: Educational implications (pp. 3-31). New York: Basic Books.

- $\quad$ Mayer, D., Caruso, R., \& Salovey, P. (1999) 'Emotional intelligence meets standards for a traditional intelligence. Intelligence, 27, 267298.

- Mayer, D., Salovey, P., Caruso, R., \& Sitarenios, G. (2001). Emotional intelligence as a standard intelligence. Emotion, 1, 232-242. doi: $10.1037 / / 1528-3542.1 .3 .232$

- $\quad$ Michel, A.(2010). the psychological effects of moderation, flexibility at the level of the load on the differences and outcomes of conscience.MA, Angelo State University.

- $\quad$ Naik, P., Harris,V., \& Forthun, L. (2013). Mindfulness: an introduction. This document is FCS2335, one of a series of the Department of Family, Youth and Community Sciences, UF/IFAS Extension. From http://edis.ifas.ufl.edu.

- Nancy, V. (2009). The Relationship Between Teacher Burnout and Emotional Intelligence: A Pilot Study (Doctoral Dissertation, Fairleigh Dickinson University.

- Pikul, M. (2015). Changes in the social and emotional wellness of students after participation in Mentoring Program. Unpublished Ph.D. dissertation, Concordia University, Chicago.

- $\quad$ Reiff, B., Hatzes, M., Bramel, H., \& Gibbon, T. (2001). The Relation of LD and Gender with Emotional Intelligence in College Students. Journal of Learning Disabilities, Jan 01, 2001 Retrieved Jan 25, 2007 from http://www.accessmylibrary.com/coms2/browse_JJ_J024

- Robitailla, A. (2008). Emotional intelligence and teachers: An explanatory study of differences between general and special 
education teachers. Unpublished Ph.D. thesis, Union Institute \& University, Cincinnati, Ohio.

- $\quad$ Scott, M., \& Barrett, B. (2004). Using staff and student time engaged in disciplinary procedures to evaluate the impact of school-wide PBS. Journal of Positive Behavior Interventions, 6, 21-27.

- Sharp, P. (2001) Nurturing Emotional Literacy. London: David Fulton.

- $\quad$ Shoaib, Ali Mahmoud (2013). Psychological pressures and psychological burning and emotional intelligence of teachers in special education programs in the city of Najran. Journal of psychological and educational studies of quality of life specialized scientific journal, Volume II, third issue, 75-94. (In Arabic).

- Silas,

D. (2018).

Emotional literacy.

https://www.specialeducationalneeds.co.uk/emotionalliteracy.html

- Stern, R. (2000). Social and emotional learning: What is it? How can we use it to help our children? Retrieved June 21, 2014 from http://www.aboutourkids.org/articles/socialemotional.html

- Sternberg, J. (2001) 'Measuring the intelligence of an idea: How intelligent is the idea of emotional intelligence?' In J. Ciarrochi, J. Forgas, and J. Mayer Emotional Intelligence in Everyday Life. London: The Psychology Press, Taylor and Francis. 187-194.

- $\quad$ Stewart-Brown, S. (2000) 'Parenting, well-being, health and disease'. In Buchanan, A. and Hudson, B. (eds) Promoting Children's Emotional Well-being. Oxford: Oxford University Press, 28-47.

- Stiner, C. (2007).Emotional Literacy; Intelligence with a heart. http://emotional-literacy-training.com/wpcontent/uploads/2015/09/Steiner-Emotional-Literacy.pdf 
- $\quad$ Sue-Chan,C., \& Latham, P. (2004). The relative effectiveness of external peer, and self-coaches. Applies Psychology: An International Review, (2), 260-278. Topping (1998) 'Promoting social competence'.www.dundee.ac.uk/psychology/prosoc.html

- The Guarantor, Saladin and Sammour, Qasim (2017). The effectiveness of a cognitive behavioral counseling program to reduce the learning deficit and improve the psychological resilience of children who are abused in public schools in Bani Kenana district. The Jordanian Journal of Educational Sciences, Vol. 13 (2), 171-191. (In Arabic).

- Watkin, C. (2002). Developing Emotional Intelligence. International Journal of Selection and Assessment, 2, 89-92.

- Zhou, M., \& Ee,j. (2012).Development and validation of the social emotional questionnaire (SECQ).The International Journal of Emotional Education,4(2),27-42.

- Zins, E., \& Elias, J. (2006). Social and emotional learning. In G. G. Bear, K. M.Minke, \& Thomas (Eds.), Children's needs III: Development, problems, and alternatives. Bethesda, MD: National Association of School Psychologists. 